\title{
PRÁTICAS EXTENSIONISTAS DE CONVIVÊNCIA COM O SEMIÁRIDO NA COMUNIDADE DE SÃO DOMINGOS, EM \\ SOBRAL/CE
}

\author{
UNIVERSITY EXTENSION PROJECTS AIMED AT \\ IMPROVING LIFE IN THE SEMI-ARID REGION OF SÃO \\ DOMINGOS, SOBRAL/CE
}

\author{
Pedro Henrique Eleoterio de Assis* \\ ORCID: https://orcid.org/0000-0002-7404-4167 \\ José Falcão Sobrinho** \\ ORCID: https://orcid.org/0000-0001-6335-6088 \\ Maria Raiane Gomes*** \\ ORCID: https://orcid.org/0000-0002-7883-7682
}

\section{RESUMO:}

A extensão universitária é um elemento essencial da identidade institucional e que tem grande potencial educacional e social. Tais práticas possibilitam a comunicação social entre a comunidade acadêmica e o meio social, promovendo o diálogo e a troca de conhecimentos. O presente estudo tem o objetivo de identificar as instituições promotoras das práticas extensionistas na comunidade de São Domingos, no município de Sobral - CE, bem como fazer uma análise da relevância social de tais práticas na comunidade. O percurso metodológico da pesquisa seguiu: i) levantamentos bibliográficos; ii) trabalhos de campo na comunidade de São Domingos. Conclui-se que os projetos de extensão na comunidade contribuíram na aprendizagem dos participantes e na troca de saberes entre os envolvidos.

Palavras-chave: Extensão universitária; Natureza; Associativismo.

\begin{abstract}
:
University extension is an essential element of the institution identity and shows great educational and social potential. These practices enable social communication between the university community and the social environment in which it is inserted, promoting dialogue and shared knowledge. This study aimed to identify the institutions that promote extension practices in the community São Domingos, in the municipality of Sobral - CE, and carry out an analysis of the social relevance of such practices in the community. The research methodology included: i) bibliographic survey, and ii) field work in the São Domingos community. Our results led to the conclusion that the extension projects in the community promoted knowledge sharing and contributed to the participants' learning process.
\end{abstract}

Keywords: University extension; Nature; Partnership.

\footnotetext{
* Geógrafo. Universidade Estadual Vale do Acaraú (UVA), Sobral - Ceará, Brasil. E-mail: pedrosaodomingo345@gmail.com ** Professor da Universidade Estadual Vale do Acaraú (UVA), Sobral - Ceará, Brasil. E-mail: falcao.sobral@ gmail.com *** Geógrafa. Universidade Estadual Vale do (UVA), Acaraú, (UVA), Sobral - Ceará, Brasil. E-mail: raiane.gomes665@gmail.com
} 


\section{Introdução}

O Nordeste do Brasil ocupa uma área de aproximadamente $1.219 .000 \mathrm{~km}^{2}$, que equivalem a torno de um quinto do território total do país. Corresponde também a uma das seis grandes zonas climáticas do Brasil e inclui as terras interiores à isoieta anual de 800 mm (CIRILO et al., 2007).

Em termos regionais, o desenvolvimento do semiárido brasileiro sempre esteve condicionado ao seu perfil edafoclimático, ao modelo sociopolítico, administrativo e gerencial adotado pelo governo nos níveis federal, estadual e municipal (CIRILO, 2008). De acordo com o IBGE (2011), a denominada região semiárida contava com aproximadamente 25 milhões de habitantes, em que pese suas características bastante severas em condições ambientais.

A convivência do homem com o ambiente semiárido é uma ação construtiva. Sempre o homem buscou alternativas para adaptar-se com o espaço em sua volta. Conforme Silva (2007), a convivência é um reaprendizado da comunhão intrínseca entre os sujeitos e a realidade do semiárido, através das experiências vividas.

No Nordeste brasileiro, a percepção de convivência com o ambiente demorou a ser internalizada pelo poder púbico, já que voltava grande parte das suas ações ao combate à seca. A seca é um fenômeno natural que tem registro histórico no Nordeste brasileiro desde o ano de 1552 (VILLA, 2001).

O meio de levar o conhecimento desenvolvido nos centros universitários até as comunidades caracteriza a extensão, que é um dos pilares do tripé da universidade. Sílveres (2012) destaca que a extensão universitária é caracterizada pela sua potencialidade educacional e social, sendo ainda um elemento essencial da identidade institucional. As práticas extensionistas são consideradas um processo educativo e pedagógico, pois possuem a possibilidade de integrar diferentes ramos dos saberes, como por exemplo: o geográfico, biológico, contábil e pedagógico. Nesta perspectiva, no ambiente semiárido as práticas de extensões se territorializam no espaço, ou seja, é na organização socioespacial que as ações são desenvolvidas no espaço vivido de cada sujeito.

Diante dos fatos supracitados, o presente estudo teve como objetivo: identificar as instituições promotoras das práticas extensionistas na comunidade de São Domingos, no município de Sobral - CE e, ainda, analisar as propostas dos projetos e suas relevâncias sociais no âmbito comunitário.

\section{A Extensão Universitária}

A extensão universitária é uma ferramenta de uso transdisciplinar. Ela consiste na transferência de saberes científicos, empíricos ou do senso comum para um público de pessoas em geral, que necessitam conhecer informações tecnológicas, educacionais e de saúde 
pública. Tais conhecimentos adquiridos podem acontecer por meio de projetos de extensão universitária, cursos educacionais pedagógicos e de prestações de serviços comunitários.

Segundo as informações apresentadas anteriormente, as atividades de extensão não se limitam apenas à universidade, pois outras instâncias podem realizar essa prática. Dessa forma, os cursos de licenciatura devem propor projetos de extensão interinstitucional para os graduandos desenvolverem ao longo do curso, podendo ser realizados em comunidades, escolas de educação básica e nos diversos setores da sociedade.

Assim, a extensão é um instrumento educativo no seio social. As instituições educativas e governamentais dispõem deste meio para as inter-relações no processo de ensinoaprendizagem e englobam os diferentes sujeitos participantes. As ações extensionistas são consideradas atividades interdisciplinares e associativas, ou seja, ultrapassam os limites territoriais. $\mathrm{O}$ saber extensionista tem a possibilidade de perpetuar, na zona rural ou no espaço urbano, mediante as possibilidades estratégicas dos indivíduos que residem distante das cidades e centros universitários, ou seja, em pequenas comunidades, vilarejos ou aldeias.

A extensão surgiu na Inglaterra, no século XIX, como a chamada "Educação Continuada" (Lifelong Education). Segundo Nogueira (2005), era destinada à população adulta que não tinha acesso à universidade, e isso acontecia por meio de cursos de curta duração para as pessoas aprenderem algumas técnicas específicas. Tais técnicas serviam para se aplicar no cotidiano, se contrapondo à visão estabelecida hoje, que é a formação inclusiva, educativa, cultural, científica e tecnológica dos envolvidos.

Nessa perspectiva, a extensão universitária, que até esse momento era entendida oficialmente como cursos ou eventos focados em um público que já participava da vida acadêmica, ou, então, como projetos assistencialistas voltados para o interesse do governo (no caso, o militar), passou a ser compreendida como um processo de maior abertura da universidade para uma relação mais ampla com a sociedade (NOGUEIRA, 1999).

No Brasil, o Decreto do Estatuto das Universidades Brasileiras do ano de 1931 não mostra a extensão como função da universidade, limitando-se à divulgação de pesquisas voltadas para uma população mais instruída. As primeiras experiências de extensão universitária no território brasileiro ocorreram na Universidade Livre de Manaus, criada em 1909, no Ciclo da Borracha, e na de São Paulo e do Paraná, em 1911 (JEZINE, 2001). Tais experiências aconteceram por meio de conferências e semanas abertas ao público. Nelas, eram trabalhados temas, porém, com o agravante de não estarem relacionados aos problemas sociais e econômicos da comunidade da época.

No entanto, a extensão universitária só se tornaria ação obrigatória nas Instituições de Ensino Superior - IES a partir do ano de 1968, de acordo coma Lei $\mathrm{n}^{\circ}$ 5.540, que concede que todas as entidades de ensinos superiores deveriam oportunizar atividades "como cursos e serviços especiais estendidos à comunidade" (FORPROEX, 2007, p.11). 
Conforme Fehlberg, Silva e Valle (2014) reiteram, após 1975, o Ministério da Educação e Cultura e o Conselho de Reitores das Universidades Brasileiras estabeleceram as definições que a extensão deveria cumprir de acordo com alguns princípios:

Somente em 1975 o MEC e o CRUB (Conselho de Reitores das Universidades Brasileiras) definiram a extensão baseados em três características básicas: oferta de serviços à população, fornecimento de material de trabalho à universidade e a integração dessas duas ênfases. (FEHLBERG; SILVA; VALLE, 2014, p.2).

Nesse novo direcionamento, onde a Extensão Universitária se apresenta no âmbito da educação superior brasileira, podemos entendê-la como uma ação social contínua que engloba diferentes agentes e que promove a intercomunicação. Nas palavras de Duch (2006), o autor conceitua a extensão como facilitadora de um modelo de transmissão e como processo educativo, cultural e científico. Portanto, tornando-se catalisadora do ensino e da pesquisa e, ainda, compondo efetivamente o tripé de sustentação do ensino superior no Brasil.

Diante dessa cronologia histórica, temos como exemplo a institucionalização formal da extensão universitária. Ela foi regulamentada por lei institucional, mas apesar disso ainda era tida como um procedimento assistencialista e que não obedecia ao caráter universitário. Em consonância com teóricos que corroboram o entendimento da extensão, podemos dizer que essas atividades são vistas como elo integrativo na formação cidadã.

Nessa perspectiva, é importante enfatizar que a Política Nacional de Extensão conceitua a extensão universitária como "processo educativo, cultural e científico que articula o ensino e a pesquisa de forma indissociável e viabiliza a relação transformadora entre a universidade e a sociedade" (FÓRUM..., 2007, p. 17).

\section{Materiais e Métodos}

Para o estudo, foi selecionada uma comunidade localizada na zona rural do município de Sobral, que está inserida na superfície sertaneja. Conforme Falcão Sobrinho (2008), a superfície sertaneja é a expressão espacial de maior significância visual, ocupa cerca de $2 / 3$ do território cearense. A primazia deste ambiente traz consigo um quadro heterogêneo no que concerne aos elementos que compõem o cenário da paisagem, seja no aspecto natural ou no aspecto social.

A comunidade de São Domingos situa-se na Zona Norte do Estado do Ceará

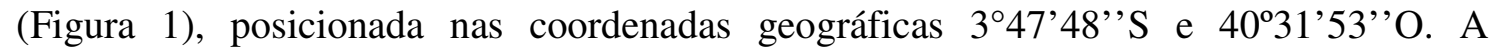
localidade dista $26 \mathrm{~km}$ do município de Sobral, tendo como sede o distrito de Jaibaras. No vilarejo, a população tem dificuldades de acesso, pois saindo da rodovia federal é preciso percorrer $6 \mathrm{~km}$ de estrada tortuosa. Também existem dificuldades para acessos a serviços básicos essenciais como a saúde, lazer e educação, seja pela falta de pavimentação da estrada ou pela falta de transporte coletivo (TRANSFERETTI; MORAES, 2010). 
Figura 1 - Mapa de localização de São Domingos, Sobral/CE.

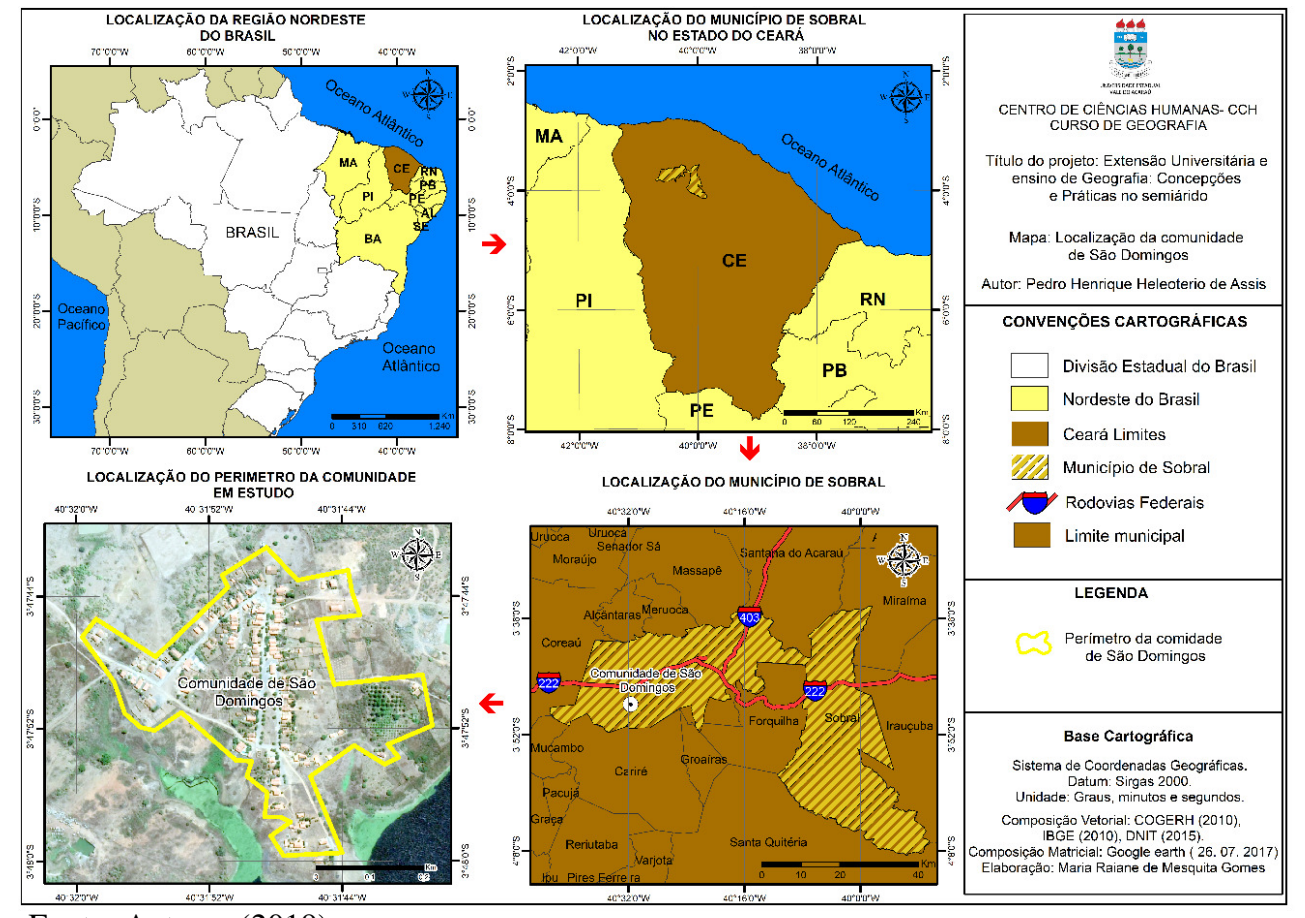

Fonte: Autores (2019).

A proposta de trabalho baseou-se em realizar observações diretas, conversas informais com os moradores e no acompanhamento das atividades de extensão. Assim, foi possível evidenciar como a extensão rural proporciona mudanças na dinâmica socioespacial do lugar, como também na percepção das pessoas envolvidas, colaborando também, dessa forma, na difusão de informações.

O estudo possui caráter qualitativo, a partir dos projetos de extensão universitária, realizados no período dos anos de 2015 a 2019. Os sujeitos que participaram formalmente da pesquisa foram classificados como agricultores rurais, que foram beneficiados com os projetos de extensão.

Para esse tipo de pesquisa foram utilizados os seguintes instrumentos metodológicos: a) Revisão bibliográfica do tema em questão, assim analisados documentos existentes em artigos científicos, relatórios dos projetos de extensão, monografias, dissertações e teses que abordam sobre o movimento extensionista no Brasil; b) Realização de visitas a campo na comunidade no intuito de conhecer o público-alvo e, por conseguinte, o nível escolar dos participantes. Deste modo, realizar rodas de conversas com os líderes comunitários e agricultores familiares para constatar a aceitabilidade dos moradores no 
início do projeto de extensão e diagnosticar as potencialidades do local em uma dinâmica socioespacial; c) Produção cartográfica de mapa de localização da área estudada.

\section{Resultados e Discussão}

O Quadro 1, a seguir, apresenta as instituições de ensino superior - IES que desenvolveram projetos de extensão na comunidade de São Domingos, com o respectivo ano de execução das atividades e a descrição do nome do projeto de extensão. Vale destacar que todas as IES descritas têm sede administrativa na cidade de Sobral, Ceará.

Quadro 1 - IES com projetos de extensão em São Domingos.

\begin{tabular}{|c|l|l|}
\hline $\begin{array}{c}\text { ANO DO } \\
\text { PROJETO }\end{array}$ & \multicolumn{1}{|c|}{ INSTITUIÇÕES } & PROJETO DE EXTENSÃO \\
\hline 2015 & Instituto Federal do Ceará - IFCE & $\begin{array}{l}\text { Implantação das boas práticas de fabricação } \\
\text { de alimentos em uma comunidade da zona } \\
\text { rural de Sobral - CE }\end{array}$ \\
\hline 2016 & Faculdade Luciano Feijão - FLF & $\begin{array}{l}\text { Beneficiando comunidade para organização } \\
\text { de produtos da caprinocultura - Projeto } \\
\text { interinstitucional }\end{array}$ \\
\hline & & Ferramentas participativas \\
\hline 2017 & $\begin{array}{l}\text { Universidade Estadual Vale do Acaraú - } \\
\text { UVA }\end{array}$ & \multicolumn{2}{|l}{} \\
\hline & & \\
\hline
\end{tabular}

Fonte: Autores (2019)

No Projeto I - "Implantação das boas práticas de fabricação de alimentos em uma comunidade da zona rural de Sobral, CE", as práticas de convivência com o semiárido tradicionalmente permanecem as mesmas, como plantação de milho, feijão e armazenamento da água da chuva em cisternas. Com isso, a seca é vista como um fenômeno divino, mas não natural. Nesse contexto, o Projeto I evidencia a implantação das boas práticas de manipulação de alimentos na localidade de São Domingos.

Assim, muitos agricultores que plantavam e/ou plantam milho ou feijão começaram a produzir alimentos derivado do leite, como: sorvete do leite de cabra e queijos, para venda externa à comunidade. Foi necessária uma capacitação/orientação técnica dos produtores sobre a maneira correta de manipular alimentos para a venda comercial. 
Dentre as atividades realizadas ao longo do projeto, destacam-se:

I- Palestra: Segurança dos alimentos;

II- Roda de Convivência: Higiene e Saúde dos alimentos;

III- Palestra: Armazenamento de alimentos;

IV- Palestra: ingredientes e embalagens; Recolhimento de produtos (RECALL).

Figura 2 - Capacitação técnica aos produtores

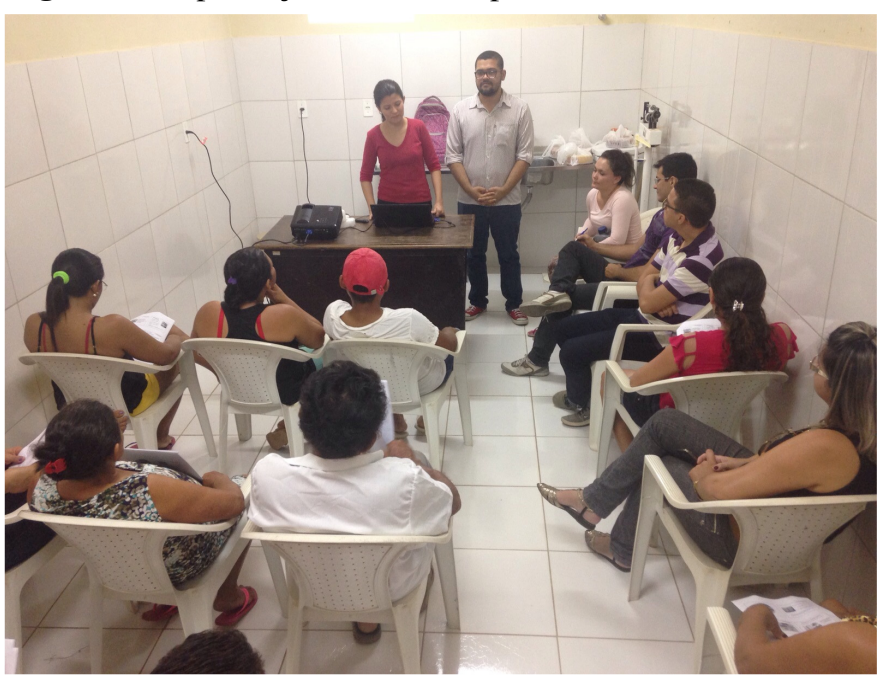

Fonte: Autores (2015).

A Figura 2 mostra uma das atividades realizadas durante o projeto, como palestras e rodas de conversas, em que ocorreu a certificação de 20 horas/aula aos participantes.

O Projeto II - "Beneficiando comunidade para organização de produtos da caprinocultura" foi inter-institucional, e teve como proposta: a) incentivo do consumo do leite caprino pelos criadores de cabra, sendo que muitos não têm o hábito de consumir o leite; b) proposta de comercialização de produtos oriundos do leite caprino.

Na comunidade, quase todas as famílias têm uma cabra, mas muitas não percebem o valor comercial agregado ao leite. Durante as atividades do projeto, ocorreu a produção de sorvetes, queijos e doces. Com isso, houve algumas ações durante o projeto:

I - Visita técnica a um capril de cabras;

II - Promoção de um curso de sorvetes com o leite de cabra.

Nesse contexto, as IES colaboradoras do projeto foram IFCE e FLF. O empreendedorismo associativo é uma característica do projeto, na geração de renda e na venda dos produtos do leite da cabra. 
O projeto III - "Ferramentas Participativas" visa transferir tecnologias consideradas prioritárias a partir de metodologias participativas aos criadores de cabra. A Figura 3 ilustra a série de cartilhas "Como criar caprinos e ovinos", que foram produzidas em conjunto tanto pela equipe do projeto como pelos criadores de cabras. A cartilha orienta os criadores a nutrirem seu rebanho de forma saudável.

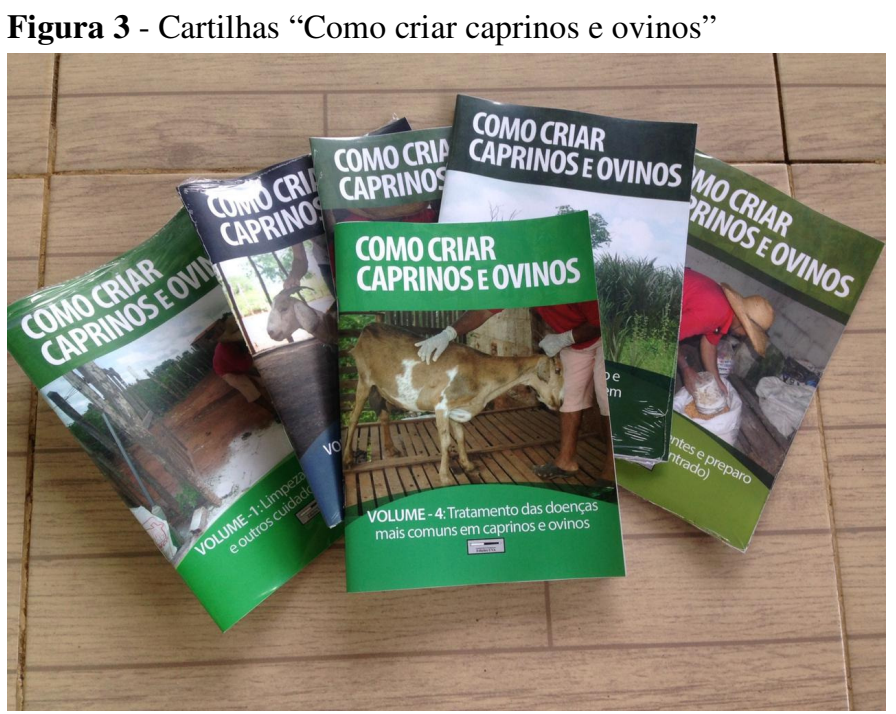

Fonte: Autores (2020)

Percebeu-se a diversidade organizacional dos projetos, atribuídos à localidade de São Domingos como o de agricultura familiar, também relacionado à alimentação orgânica e organização produtiva, onde foi desenvolvido um sítio comunitário com produção de frutas orgânicas. Vale ressaltar que a comunidade também é pioneira na criação de cabras leiteiras. Mota (2016) analisou a organização produtiva e os saberes locais dos criadores de caprinos da comunidade de São Domingos.

Com a visita a campo, foi possível identificar as tecnologias sociais de convivência com o semiárido, como: Mandala, Quintal Produtivo, Produção Agroecológica Integrada e Sustentável - PAIS e Cordões de Pedras. As respectivas tecnologias são fruto das assistências técnicas de órgãos governamentais, como a Empresa de Assistência Técnica e Extensão Rural do Ceará (Ematerce) e a Secretaria de Agricultura e Pecuária de Sobral (Seagri). Tais órgãos auxiliam os produtores nas suas atividades de campo e são também ações extensionistas, no entanto, não universitárias.

O verde e cinza é o constante da paisagem do semiárido, onde, no período do inverno, a vegetação floresce, os reservatórios aumentam a carga hídrica e, assim, as pessoas cultivam alimentos como o milho e o feijão. No período do verão, as folhas da vegetação caem e as chuvas diminuem. 
Nesse sentido, as tecnologias sociais ajudam o homem do campo em suas diversas atividades, o armazenamento de água é um dos principais fatores que a cisterna proporciona de melhoria. Almeida (2017) estabeleceu uma análise integrada da paisagem na superfície sertaneja de Frecheirinha - CE, ao correlacionar a integração dos elementos da natureza aos aspectos socioeconômicos, relacionando as cisternas de placas como alternativa de convivência com o semiárido em regiões com ausência de chuvas. As cisternas amenizam a problemática da falta de água.

Dentre as alternativas de convivência com o semiárido em São Domingos, existem algumas como os Cordões de Pedras e Mandala, que são apresentados nas Figuras 4 e 5, respectivamente. Com relação à cisterna de placa, na comunidade não existe a referida tecnologia, pois na localidade existe um açude público - Açude Ayres de Sousa onde é realizado o abastecimento nas residências.

Os cordões de pedra são uma alternativa sustentável, onde não são retirados os recursos naturais da natureza para transformação. As rochas ficam em volta de áreas de produtividade agrícola e visam à diminuição da perda de solo no plantio. Na Figura 3, é possível observar que os cordões de pedra estão em volta de mangueiras, evitando que o solo seja arrastado para locais de declividade e evitando a erosão do solo.

A Ematerce é um dos órgãos que acompanha os produtores na localidade. Orientados nas atividades agrícolas e pecuárias, os cordões de pedras foram construídos pelos próprios agricultores, e tais ações não são consideradas ações extensionistas.

Figura 4 - Cordões de Pedra

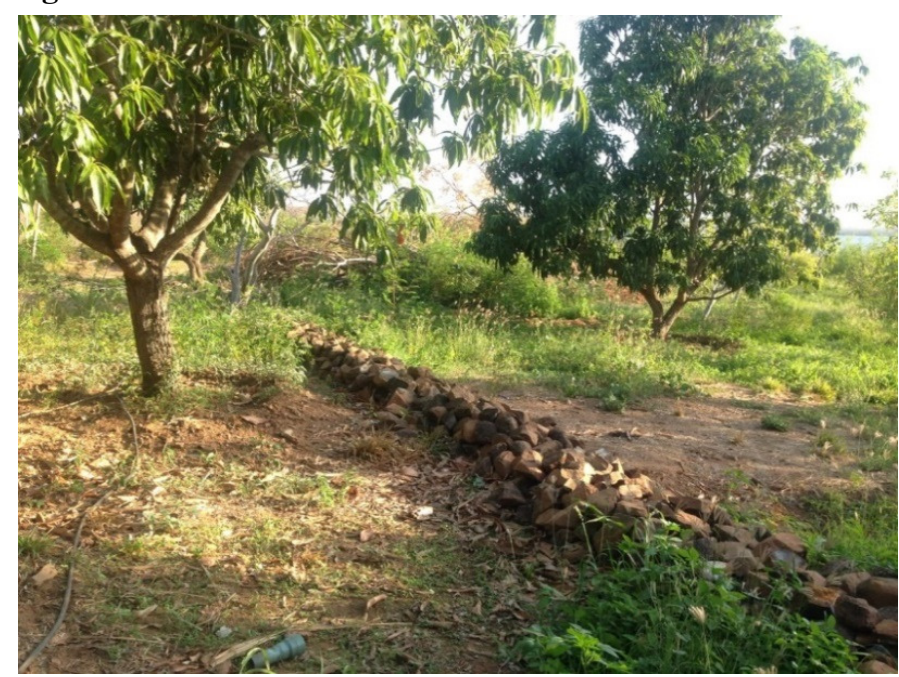

Fonte: Assis (2019) 
Na Figura 5, o Mandala constitui um aspecto visível na paisagem, tecnologia de convivência com o semiárido que se apresenta de importância natural e ecológica para a natureza. O Mandala, localizado no sítio comunitário de São Domingos, constitui uma tecnologia que oferece qualidade de vida para as pessoas que consomem frutas e verduras produzidas em sua volta. Por todas serem orgânicas, considera-se um conjunto sistêmico que consiste na integração entre elementos que se inter-relacionam, e sua estrutura consiste em um sistema de irrigação e animais ao seu redor.

O sistema agroecológico que se refere ao mandala constitui-se na produção de verduras, salsinhas, frutíferas, como a bananeira e algumas ervas medicinais. A irrigação é realizada das águas do açude Ayres de Sousa, que fica às margens do sítio. O processo de irrigação é por gotejamento, isso faz com plantas e legumes fiquem com uma quantidade de água mais acentuada no solo e também acarreta o desperdício menor de água.

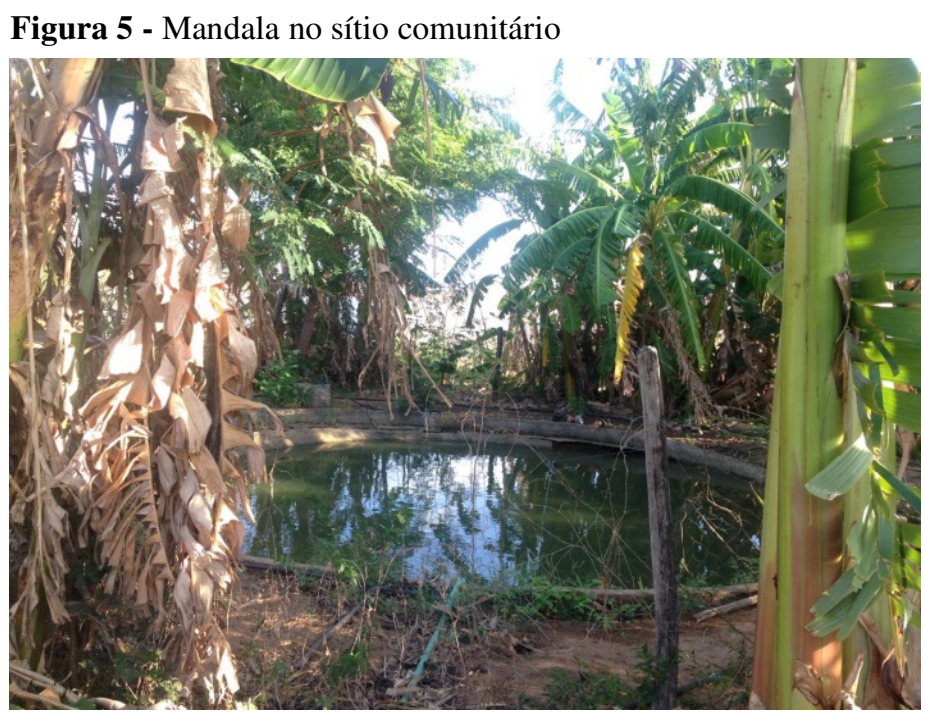

Fonte: Assis (2019)

Nesse ponto de vista, os solos da região semiárida apresentam alguns fatores que impossibilitam dificuldades em seu manejo. Portanto, a orientação por meio desses projetos sobre as técnicas de manejo e conservação do solo, tais como a rotação de culturas, curvas de nível etc., são de grande relevância. $O$ homem do campo necessita conhecer instruções técnicas que facilitem a produção agrícola, e tais saberes têm sua valorização científica nas diversas áreas, como a educacional, científica ou do senso comum.

Através do acompanhamento técnico da Prefeitura Municipal de Sobral e de outras instituições, a qualidade de vida dos moradores melhorou bastante. Percebem-se as noções de coletividade e do associativismo entre os habitantes, isso devido a cursos de 
formação com os quais são beneficiados. Uns ajudam os outros nas atividades do campo, ações de cunho extensionistas e, também, problemas interpessoais. Atualmente, a localidade se organiza de maneira coletiva, com a criação da Associação Comunitária. A comunidade dispõe de elementos estruturais públicos, como a praça pública e o anexo escolar para o público infantil. A economia local gira em torno da agricultura familiar, pecuária e pesca extensiva.

\section{Considerações Finais}

A extensão universitária é um instrumento na formação acadêmica de estudantes universitários. O referido saber se difunde nas diversas instâncias da sociedade, de modo que a extensão tende a promover a troca de saberes entre as partes, ocasionado a integração dos saberes por meio de projetos de extensão.

Quando as universidades ultrapassam seus muros para realizar extensão, o público externo se beneficia diretamente. No caso de um projeto de extensão realizado em escolas, a referida atividade motiva os alunos e professores. A extensão tem como incumbência divulgar o conhecimento científico, e quando tais atividades são realizadas em pequenas comunidades os indivíduos se beneficiam, ocasionando a troca de saberes entre os docentes, discentes da universidade e a sociedade.

As áreas do conhecimento científico, como Geografia, Pedagogia ou Psicologia têm separações analíticas do saber, sem ligação entre tais conjuntos. Assim, a extensão tem como intuito promover a interdisciplinaridade entre os saberes, cada conhecimento tem sua contribuição no seio da sociedade.

Portanto, as diferentes instituições - seja escolas, hospitais ou prefeituras locais devem buscar a integração entre a universidade e a sociedade. A parceria de tais instituições com a comunidade externa promove a construção dos saberes. A escola e a universidade devem caminhar juntas para a promoção de projetos e atividades disciplinares, construindo projetos de extensão, pesquisa, além de valorizar o conhecimento empírico das pessoas que não dispõem de saberes técnicos produzidos nas universidades. Tais práticas objetivam resultados concretos e fazem com que a função educativa seja um instrumento de ação.

No caso da comunidade de São Domingos, as práticas de extensão contribuíram significativamente na promoção do conhecimento dos participantes. Foi possível promover a interação entre os sujeitos e, assim, os saberes populares das pessoas trouxeram contribuição direta no processo de ensino-aprendizagem. 
Agradecimentos: Programa de Bolsas de Permanência Universitária - PBPU, Laboratório de Pesquisa e Extensão do Semiárido - LAPES/UVA.

\section{Referências}

ALMEIDA, C. L. A convivência com o semiárido a partir do uso de cisternas de placas na zona rural do município de Frecheirinha - CE: Dimensões na paisagem da superfície sertaneja. 2017. 162 p. Dissertação (Mestrado em Geografia) - Universidade Estadual Vale do Acaraú, Sobral, 2017.

CIRILO, J.A.; CABRAL, J.J.S.P., FERREIRA, J.P.L., OLIVEIRA, M.J.P.M., LEITÃO, T.E., MONTENEGRO, S.M.G.L.; GÓES, V.C. O uso sustentável dos recursos hídricos em regiões semi-áridas. Recife: ABRH, Editora Universitária da Universidade Federal de Pernambuco, 2007. p.167-175.

CIRILO, J.A. Políticas públicas de recursos hídricos para o semi-árido. Estud. av. [online], v.22, n.63, p.61-82, 2008. Disponível em: https://doi.org/10.1590/S010340142008000200005. Acesso em: 22 abr.2020.

DUCH, F.F. Interface extensão universitária e cultura interdisciplinar. $97 \mathrm{f}$. Dissertação (Mestrado)- Universidade Braz Cubas, Mogi das Cruzes, 2006.

FÓRUM de Pró-Reitores de Extensão das Universidades Públicas Brasileiras. Extensão Universitária: organização e sistematização. Org. Edison José Corrêa. Belo Horizonte: Coopmed, 2007. Disponível em: <http://www.cedaf.ufv.br/dxt/anexos/pagina/arquivos/2358.pdf $>$. Acesso em: 13 jan. 2016.

FALCÃO SOBRINHO, J. O Relevo como âncora da Paisagem do Vale, Verde e Cinza, do Acaraú, no Estado do Ceará. 2008. Tese (Doutorado em Geografia Física) Universidade de São Paulo, São Paulo, 2008.

FEHLBERG, J.; SILVA, M.C.; VALLE, P.C. Eu, meus filhos e nossa escola: pensando a extensão universitária na escola regular. Psicologia em Foco, v.4, n.1, p.1-7, 2014.

INSTITUTO BRASILEIRO DE GEOGRAFIA E ESTATÍSTICA - IBGE. Censo Demográfico 2010. Rio de Janeiro: IBGE, 2011. 
JEZINE, E. M. Multidiversidade e extensão universitária. In: FARIA, Doris Santos de (Org.). Construção conceitual da extensão na América Latina. Brasília: UnB, 2001.

MOTA, T. L. N. da G. Inovação, sustentabilidade e organização produtiva: a caprinocultura na Comunidade de São Domingos, Sobral - CE, 2016. 123 p. Tese (Doutorado em Desenvolvimento e Meio Ambiente) - Universidade Federal do Piauí, 2016.

NOGUEIRA, M. das D. P. Políticas da Extensão Universitária Brasileira. Belo Horizonte: Ed. UFMG, 2005.

NOGUEIRA, M. das D. P. Políticas de extensão universitária brasileira 1975 - 1999. Dissertação (Mestrado em Educação) - Faculdade de Educação, Universidade Federal de Minhas Gerais, Belo Horizonte, 1999.

SÍVERES, L. Processos de aprendizagem na extensão universitária. Goiânia: Editora PUC Goiás, 2012.

SILVA, R. M. Entre o combate à seca e a convivência com o Semiárido: políticas públicas e transição paradigmática. Revista Econômica do Nordeste, Fortaleza, v. 38, n. 3, jul.set. 2007.

TRANSFERETTI, S. G. C.; MORAES, T. G. Projeto Cabra Nossa de Cada Dia Sobral: Conexão Local - Relatório Final. Escola de Administração de Empresas de São Paulo, Fundação Getúlio Vargas, 2010.

VILLA, M. A. Vida e morte no sertão, São Paulo: Ática, 2001. 